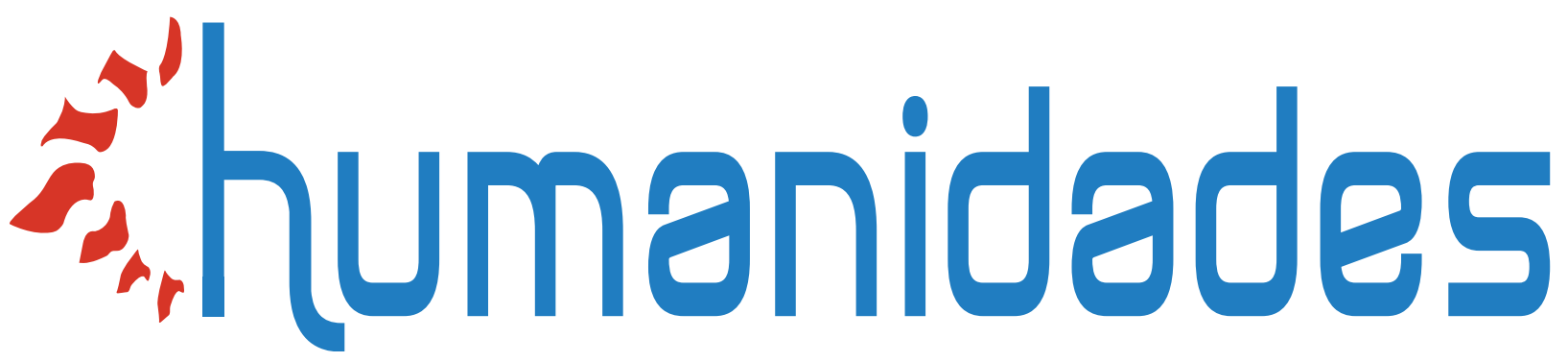

\title{
Autonomía e interdependencia. La ética del cuidado en la discapacidad
}

\author{
Diego Carmona Gallego
}

DOl: https://doi.org/I0.155 I7/h.v10i2.4II54 https://revistas.ucr.ac.cr/index.php/humanidades/index 


\title{
"humanidades
}

Revista Humanidades

ISSN: 2215-3934

humanidades@ucr.ac.cr

Universidad de Costa Rica

Costa Rica

\section{Autonomía e interdependencia. La ética del cuidado en la discapacidad}

\author{
Carmona Gallego, Lic. Diego \\ Autonomía e interdependencia. La ética del cuidado en la discapacidad \\ Revista Humanidades, vol. 10, núm. 2, 2020 \\ Universidad de Costa Rica, Costa Rica \\ Disponible en: http://www.redalyc.org/articulo.oa?id=498062469003 \\ DOI: https://doi.org/10.15517/h.v10i2.41154
}

Esta obra está bajo una Licencia Creative Commons Atribución-NoComercial-SinDerivar 3.0 Internacional. 
Desde las ciencias sociales, la filosofía y la educación

\title{
Autonomía e interdependencia. La ética del cuidado en la discapacidad
}

\author{
Autonomy and Interdependence. The Ethics of Care and Disability \\ Lic. Diego Carmona Gallego \\ Instituto Rosario de Investigaciones en Ciencias de la \\ Educación - CONICET/ Universidad Nacional de Rosario \\ (UNR). Universidad Nacional de Entre Rios (UNER), \\ Argentina \\ carmona@irice-conicet.gov.ar \\ (iD) http://orcid.org/0000-0002-3089-4936
}

DOI: https://doi.org/10.15517/h.v10i2.41154
Redalyc: http://www.redalyc.org/articulo.oa?
id $=498062469003$

Recepción: 21 Noviembre 2019

Aprobación: 09 Marzo 2020

\section{Resumen:}

El presente trabajo recorre las nociones de autonomía, cuidado e interdependencia, como claves que permitan reflexionar sobre las prácticas profesionales en el campo de la discapacidad. Se propone ahondar en los posibles sentidos, así como las convergencias y tensiones existentes entre estos conceptos. Postulamos que en la medida en que el concepto de autonomía se reduzca al de independencia, se corre el riesgo de componer prácticas afines al capitalismo neoliberal. Este último entendido no solo como sistema económico, sino como orden productor de subjetividades en torno al individualismo, la competencia, el consumismo y el desgarramiento de los vínculos. En contraste, proponemos articular autonomía y ética del cuidado. El cuidado permite visibilizar las redes afectivas y materiales que sostienen la vida. Lejos de una categorización estática y dicotómica que clasifica a las personas en "independientes" y "dependientes", postulamos la necesidad de toda vida, de ser cuidada. De esta manera, se trata en todo caso de diferentes flujos de intensidades en las necesidades de cuidado. A partir del acoplamiento entre cuidado y autonomía finalizamos este escrito con la propuesta del concepto de "autonomía interdependiente".

Palabras ClaVe: autonomía, cuidado, interdependencia, discapacidad.

\section{Abstract:}

The present work approach the notions of autonomy, care and interdependence, as keys that allow us to reflect on professional practices in the field of disability. It is proposed to delve into possible senses, as well as convergences and tensions between these concepts. We postulate that to the extent that the concept of autonomy is reduced to that of independence, there is a risk of composing practices related to neoliberal capitalism. The latter understood not only as an economic system, but as a producer order of subjectivities around individualism, competition, consumerism, and the tearing of ties. In contrast, we propose to articulate autonomy and ethics of care. Care makes visible the affective networks and materials that sustain life. Far from a static and dichotomous categorization that classifies people as "independent" and "dependent," we postulate the need for care of all lives. In this way, it is in any case different flows of intensities in care needs. From the coupling between care and autonomy, we finalize this writing with the proposal of the concept of "interdependent autonomy".

KEYWORDS: authonomy, care, interdependence, disability.

\section{INTRODUCCIÓN}

Son de utilización frecuente en el campo de la discapacidad ${ }^{1}$ términos como autonomía, independencia y autovalimiento, aunque en muchas ocasiones de manera indistinta y ambigua, sin mayores precisiones conceptuales. De acuerdo con Contino (2017) esta situación hace que aún no sea posible encontrar con claridad las formas en las que se puede pensar la cuestión de la autonomía en relación con la discapacidad.

En el presente escrito, nos abocaremos al complejo desafío de pensar la interrelación entre autonomía, dependencia, independencia, interdependencia y cuidado. Recorreremos estas nociones como claves que posibiliten reflexionar sobre las prácticas profesionales en el campo de la discapacidad. Asumiendo que, lejos 
de ser solo cuestiones de terminología, los conceptos permiten alumbrar diferentes modos de pensamiento y sensibilidades, reflejan distintas concepciones y prácticas que integran un quehacer profesional. De esta manera, proponemos ahondar en las articulaciones y/o posibles tensiones entre los conceptos mencionados.

Reflexionamos en un contexto determinado. El mismo no es algo que simplemente "nos rodea" influyendo en mayor o menor medida, sino que más bien nos atraviesa. Es parte de las metas de nuestras prácticas profesionales, los objetivos de los programas de trabajo y el modo en que nos vinculamos. Nos atraviesa un contexto y lo construimos como agentes. Por ello asumimos esta apuesta a la reflexión en una textura sociohistórica específica. Por un lado, asistimos a un auge del neoliberalismo, entendido este no solo como sistema económico sino como orden productor de subjetividades autosuficientes, productivas, individualistas y competitivas. Por otro lado, proliferan las militancias feministas, las cuales interpelan prácticas e idearios naturalizados en torno a las jerarquías y la dominación, así como también se proponen gestar nuevos modos de ser y estar con otros.

Como veremos en este recorrido que proponemos, el neoliberalismo y los activismos feministas serán dos ejes claves para reflexionar sobre la independencia y el cuidado. Este recorrido es parte de una investigación titulada "Estudio sobre las percepciones del cuidado y su relación con las prácticas en los contextos organizativos". La misma se encuentra radicada en el Instituto Rosario de Investigaciones en Ciencias de la Educación (IRICE) y es financiada por el Consejo Nacional de Investigaciones Científicas y Técnicas $(\mathrm{CONICET})^{2}$.

\section{SOBRE AUTONOMÍAS, INDEPENDENCIAS, INTERDEPENDENCIAS}

\section{1. Tres aproximaciones al concepto de autonomía}

Etimológicamente, autonomía se puede desglosar en auto y nómos. Ambos términos de origen griego, significan: 'por sí mismo' y 'reglas o normas'. El filósofo y psicoanalista Cornelius Castoriadis (2006) afirma que son autónomas aquellas sociedades que son lúcidas respecto al carácter artificial de sus instituciones. Es decir, al hecho de que los sentidos que penetran la vida de una sociedad, la dirigen y la orientan, son producidos por esa misma sociedad.

Desde esta perspectiva, la autonomía de cada sujeto se articula con una dimensión colectiva, se compone junto con otros. Implica la confección de las leyes, reglas y significaciones en el marco de redes de relaciones en las que el sujeto se encuentra inmerso. Es decir, no existe ningún origen extrasocial de las leyes y significaciones sociales. Una primera aproximación a la autonomía, por lo tanto, afirma su carácter colectivo, no puede concebirse sin los otros y no se traza sin efectos en la propia singularidad de cada sujeto.

Si pensamos la relación entre autonomía y discapacidad, debemos situar la búsqueda de la autonomía en articulación con el llamado "modelo social" y el más reciente "modelo de la diversidad funcional". Palacios (2008) sostiene que a lo largo de la historia se han construido tres modelos de abordaje de la discapacidad. Cada uno caracterizado por diferentes respuestas jurídicas y sociales a las personas con discapacidad. Estos tres modelos son: modelo de prescindencia, modelo rehabilitador y modelo social.

El primero de ellos estableció un origen religioso en la discapacidad y propuso la prescindencia de las personas con discapacidad. Ya sea a partir de políticas eugenésicas o bien recurriendo a la marginalidad y el sometimiento. El segundo modelo ubicó y ubica las causas de la discapacidad en un orden médico-científico. Si bien ya no se considera que la sociedad pueda prescindir de las personas con discapacidad, se prescribe la necesidad de su "rehabilitación" a fin de adecuarse a un determinado modelo de normalidad. "El modelo médico sitúa la discapacidad exclusivamente en el cuerpo del individuo y fija todo su empeño en curarlo mediante tratamientos particulares, aislando a la persona como enferma y defectuosa" (Toboso y Guzmán, 2010, p. 72). Este modelo aún se encuentra reflejado en numerosas prácticas, instituciones y sentidos que 
atraviesan el quehacer profesional. Sin embargo, coexiste con el llamado "modelo social", configurándose en muchas ocasiones a partir de ello ciertas zonas híbridas o de mestizaje entre ambos modelos.

El modelo social, en cambio, surge en la segunda mitad del siglo XX. Tiene como antecedente inmediato el Movimiento de Vida Independiente, cuyos orígenes son situables en Estados Unidos, específicamente en la Universidad de Berkeley, California. Este último se gesta en el contexto de diversas luchas y demandas colectivas por derechos civiles que signaron la década de 1960 (Guzmán, Toboso y Romañach, 2010). A partir de este ponderable antecedente es que se despliega el modelo social, primer abordaje en cuya confección participan los colectivos involucrados, es decir, las personas con discapacidad.

El modelo social busca generar las transformaciones sociales que impiden que las personas con discapacidad puedan vivir de acuerdo a sus derechos, propiciando la participación e inclusión social. Promueve principios como la no-discriminación, la accesibilidad universal, el respeto por la diversidad humana y la autonomía de la persona para decidir acerca de su propia vida. Desde el modelo social, se trata de transformar la sociedad, situando la causa de la discapacidad ya no en el sujeto sino en la dimensión colectiva.

Aunque este modelo afirma que en las personas pueda haber un déficit ${ }^{3}$, el mismo no implica necesariamente una discapacidad. Lo que configura una discapacidad es en definitiva la falta de adecuación de la sociedad que genera barreras para las personas con discapacidad ante sus diferencias, en este sentido, se afirma así la necesidad de transformación social en múltiples dimensiones: simbólica, afectiva y material, de manera que esto logre posibilitar que todas las personas puedan participar activamente en la comunidad. De este modo, la autonomía es concebida, desde este modelo, como la libertad en la toma de decisiones. Por ello se propone apoyos a las personas con discapacidad para que puedan tomar estas decisiones y no la sustitución de su voluntad (Palacios, 2008).

En este sentido, una segunda aproximación al concepto de autonomía, nos permite relevar la importancia de que las personas con discapacidad puedan tomar decisiones acerca de cómo vivir la propia vida. La autonomía se entrama de esta manera con la libertad para decidir. Sin embargo, en la actualidad, esta definición de autonomía ya no es promovida solamente por el modelo social. En los últimos años ha surgido al calor del activismo del colectivo español Foro de Vida Independiente y Divertad ${ }^{4}$ (FVID), un modelo que, aun apoyándose y reconociéndose en el modelo social, presentará algunas diferencias con el mismo, aquí nos referimos al modelo de la diversidad funcional. Este busca reapropiarse de las diferencias que presentan las personas con discapacidad, calificadas socialmente como negativas, en un sentido positivo. Así es que, lejos de atribuir a estas diferencias un sentido de deficiencia o limitación, se considera que se trata de una expresión más de la diversidad humana.

Tal como sostuvo el investigador y activista Guzmán Castillo (2010): "El término diversidad funcional permite a las personas con discapacidad establecer una relación positiva con sus diferencias orgánicas y funcionales, sin desfavorecer la labor del modelo social en denunciar su situación de colectivo oprimido socialmente" (p. 149). De acuerdo con este modelo toda la sociedad puede enriquecerse al apreciar las diversas formas de movimiento, intelección, conocimiento e interrelación entre los sentidos. El énfasis del concepto de diversidad funcional está puesto por tanto en el enriquecimiento que supone para la diversidad humana, tanto la diversidad funcional como otras diversidades, tales como la sexual, étnica, cultural y de nacionalidad.

La transición del concepto de discapacidad al de diversidad funcional supone importantes transformaciones epistémicas y éticas. El desplazamiento semántico se basa en la consideración de una ética de las diversidades y en un modo de concepción de las diferencias que no son interpretadas desde el formato normal/deficitario. Asimismo, en el modelo de la diversidad se reintroduce la experiencia de la corporalidad, la cual permanece opacada en el concepto de discapacidad.

Resulta crucial la distinción entre capacidad y funcionamiento, aludiendo por este último término a las diferentes formas en que una capacidad puede ser llevada adelante. En este sentido, "las personas con discapacidad no carecen de capacidades, sino que las ponen en funcionamiento a través de funcionalidades diversas, que no coinciden con la más frecuente o habitual” (Toboso y Guzmán, 2010, p. 76). Por ejemplo, 
todos los seres humanos podemos contar con la capacidad de desplazamiento, sin embargo, los modos en que llevamos adelante estas capacidades no son homogéneos. De esta manera, podemos desplazarnos caminando, en silla de ruedas, en auto, transporte público. A pesar de ello, suele considerarse que hay un modo de funcionamiento único (el mayoritario) que se coloca en equivalencia con la capacidad. En síntesis, una tercera aproximación al concepto de la autonomía es su convergencia con el modelo social y el modelo de la diversidad funcional.

\subsection{Nada sobre nosotros sin nosotros}

Estas definiciones sobre la autonomía nos recuerdan que los colectivos de personas con discapacidad han postulado la importancia de la vida independiente. Muchos de ellos, nucleados en el Movimiento de Vida Independiente, extendieron su filosofía por Estados Unidos y luego tuvieron gran influencia en países como Suecia, Canadá e Inglaterra (Palacios, 2008). De acuerdo con el colectivo español de personas con discapacidad, Foro de Vida Independiente y Divertad (FVID), el objetivo principal de este movimiento fue la participación en la comunidad.

Sin profundizar de manera exhaustiva en esta historización, asumimos la necesidad de inscribir la reflexión que proponemos en diálogo con las voces de los colectivos mencionados. La vida independiente ha sido afirmada por los mismos como modo de recuperar las posibilidades de decisión y control sobre sus propias vidas, así como la participación social. En un contexto de fuerte opresión social y marginación, decir independencia es el modo de dar nombre a la necesidad de las personas con discapacidad de ser tratados como sujetos-agentes y no como objetos. Ello implica la asunción de un reconocimiento. Nadie conoce mejor qué necesita y desea que la misma persona con discapacidad. De allí una expresión de sentido que aún hoy, por su necesidad, prolifera: Nada sobre nosotros sin nosotros. Esto no excluye que en muchas situaciones estas necesidades y deseos ameriten ser interpretados por un otro. Ya sea porque no le son transparentes a la persona, o bien porque su discapacidad le impide poder expresarlo de una manera que le resulte clara a su interlocutor. Es conveniente considerar aquí la heterogeneidad de discapacidades que pueden existir. En cualquier caso, se trata de poder situar a la persona como sujeto/agente más que como objeto. Si una persona no conoce qué desea y necesita con claridad, ello no debería habilitar situaciones de opresión o dominación en el vínculo que se conforma.

De acuerdo a lo anterior, resulta de relevancia la Convención de Derechos de las Personas con Discapacidad (CDPD), sancionada por la Organización de las Naciones Unidas (ONU). La misma está basada en el "modelo social" y en su confección han participado personas con discapacidad. En ella se establecen derechos fundamentales que nuestras sociedades deben garantizar y se conforma un marco jurídico que busca proteger contra el abuso de poder y crear un espacio para el desarrollo humano (Quinn y Degener, 2002). Los valores que orientan este instrumento legal son: la dignidad, la autonomía, la igualdad y la solidaridad. Se trata de reafirmar que todas las personas deben ser tratadas como sujetos y no como objetos. En relación con la autonomía, la CDPD postula el derecho a la libre determinación y a la libertad de la que deben gozar las personas para sus elecciones vitales, así como el apoyo para que estas decisiones puedan ser llevadas adelante.

\subsection{Autonomía e independencia. ¿Equivalentes o diferentes?}

En muchas ocasiones, el término autonomía es sustituido por el término independencia, configurándose, como adelantamos al comenzar este trabajo, una ambigüedad y/o imprecisión entre ambas expresiones. En ciertas oportunidades se utilizan para mencionar las mismas dimensiones vitales, mientras que, en otras ocasiones, más bien permite nombrar aspectos diferenciados. 
Podemos distinguir, más allá del modo en que sean nombrados, al menos dos aspectos y/o dimensiones de la vida. Por un lado, la posibilidad de tejer las propias decisiones y llevarlas adelante. Por otro, poder hacer las cosas por sí mismo, sin asistencia y/o ayuda de otros. A lo primero, en el presente trabajo, lo llamaremos autonomía, por su parte, lo segundo será reconocido como independencia. Algunos autores distinguen estas diferentes dimensiones vitales con los conceptos de "autonomía de decisión" y "autonomía de ejecución" (Fine y Glendinning, 2005), sin embargo, no existe consenso en la definición de cada uno de estos términos.

Esta heterogeneidad se evidencia en las definiciones que el colectivo español Foro de Vida Independiente y Divertad (FVID) realiza sobre ambos conceptos. Para el mismo, independencia es poder decidir qué se quiere y/o necesita y cómo hacerlo, en cambio, autonomía remite a la dimensión del autovalimiento; es decir, efectuar una decisión sin ayuda ni asistencia. Uno de los integrantes de dicho espacio manifiesta: "Precisamente las personas que reclamamos vida independiente somos las que más apoyo necesitamos para algunas cosas [...]" (Agulló et al., 2011, p. 96).

Siguiendo a Oliver (1990) las personas con discapacidad generalmente definen la independencia considerándola como la capacidad de autocontrol y de toma de decisiones sobre la propia vida, más que la realización de actividades sin necesidad de asistencia. Así lo recuerda el integrante del foro mencionado anteriormente: "Lo mismo da ponerte el calcetín solo o con ayuda, lo importante es que decidas quién, cómo y qué calcetín te ponen” (Agulló et al., 2011, p. 97).

Esta definición de la independencia abonada por muchas personas con discapacidad es lo que en el presente trabajo llamamos autonomía. Más allá del término que se adopte, creemos importante distinguir dos aspectos diferentes de las vidas de las personas: el poder hacer actividades sin ayuda y el poder tomar decisiones acerca de la propia vida. Llegados a este punto, podemos concluir que, de acuerdo al contexto, independencia y autonomía se utilizan de manera equivalente o diferenciada. Por otra parte, un sentido que circula en (y entre) estos términos refiere a la autosuficiencia, el no depender de nada ni de nadie.

\subsection{La interdependencia}

Sin embargo, la posibilidad de tomar decisiones acerca de la propia vida, así como de gestar nuevos modos de vivir y relacionarse, no se opone a la idea de que necesitemos de otros. La mutua dependencia no excluye la posibilidad de desarrollar la autonomía, más bien, es condición imprescindible para la misma. Depender del otro no quiere decir que sea siempre y en toda situación, estar sujeto a su dominio. En muchas ocasiones, las posibilidades de ampliar nuestros horizontes y de enriquecer nuestras posibilidades se fundan en nuestras formas de relación con los otros (Candioti, 2012).

Desde esta perspectiva que planteamos, la posibilidad de decidir sobre la propia vida puede ser bloqueada o potenciada por los vínculos de la trama en la que se encuentra inmerso el sujeto. Pero de ninguna manera el sujeto puede estar fuera de esa red vincular, es decir, la interdependencia no es una elección, sino el modo en que las vidas de todas las personas son sostenidas. Por lo tanto, el desafío no radica en promover la nodependencia de esos vínculos, por el contrario, se trata de potenciar las posibilidades de decidir de la persona con discapacidad en cada momento. Lo opuesto, es decir, una noción de individuo independiente entendido como autosuficiente, puede llevarnos a una falsa idea, aquella que afirma: se puede sostener la vida sin los otros.

\section{EL NEOLIBERALISMO COMO ORDEN PRODUCTOR DE INDIVIDUOS INDEPENDIENTES}

El ideal de individuo independiente, racional, desprovisto de afectos y relaciones, separado incluso de su propio cuerpo, es característico de la modernidad. Como afirma María Teresa Martín (2010): 
En las sociedades occidentales modernas, la condición ciudadana sigue vinculada a una noción de individuo independiente, autosuficiente, ligado a la posesión de propiedades y otros recursos materiales. Sin embargo, esta idea de ciudadanía olvida que todos los seres humanos somos interdependientes, que la dependencia es consustancial a la existencia humana (p. 57).

Esta concepción de sujeto articulada con la noción de ciudadanía, se hiperboliza en función de una búsqueda de productividad, consumo, rendimiento y éxito en el marco del capitalismo neoliberal. Con este último término nos referimos a un orden socioeconómico que promueve políticas económicas como la desregulación de las finanzas, el libre comercio, la centralidad de los mercados, el desfinanciamiento de los servicios y programas sociales estatales dedicados a la salud, la educación y la cultura. Pero también pretendemos con él hacer mención a la promoción de determinadas formas subjetivas.

La subjetividad que promueve el neoliberalismo es la de un individuo autosuficiente que podría existir de manera aislada y que debe depender lo menos posible de los otros, con el fin de ser lo más competitivo posible en el mercado. Un sujeto capaz de obtener éxito a pesar de que ello se traduzca en una pérdida y/o destrucción de sus vínculos. La privatización de la existencia, la autosuficiencia en el cuidado y el intento de desgarrar los vínculos se convierten así en características distintivas del llamado enfoque neoliberal (López, 2014).

Si reducimos la autonomía a la independencia, lo importante radica, ya no en la posibilidad de decidir, de acuerdo a las propias necesidades y deseos, sino en ser individuos autosuficientes. Desde este enfoque, no se trataría tanto de que las prácticas profesionales posibiliten a los sujetos con discapacidad decidir acerca de cuestiones importantes y/o cotidianas de sus vidas, con o sin asistencia, sino que más bien, se promueve que puedan hacer actividades solos, sin ayuda ni asistencia de nadie, de manera independiente. Sobre este punto Chiara Cerri afirma que "la autonomía se reduce al individualismo propio de una ideología caracterizada por la puesta en valor de la independencia de todos los lazos y de todas las obligaciones sociales" (Cerri, 2015, p. 126).

Por consiguiente, la pregunta que se nos impone es: ¿quién es absolutamente independiente? ¿Cómo se construiría y mantendría un mundo (en) común si todos fuésemos absolutamente independientes? Desde la perspectiva que asumimos, distinguir autonomía de independencia resulta fundamental para atravesar el imaginario de un individuo autosuficiente, nodal para el orden sociopolítico y económico neoliberal. Para Benasayag y Schmit (2010) vivimos en una sociedad en la que los vínculos son vividos como restricciones o como contratos. La búsqueda de la independencia está relacionada, para ambos autores, con una concepción de la libertad fundada en la dominación: libre es aquel que domina. Por tanto, se busca dominar el propio cuerpo, el tiempo y a los otros. Este dominio no tiene que ver con las propuestas de sabios de diferentes filosofías antiguas, sino con la búsqueda de una vida competitiva y utilitaria.

Una forma de pensar el par independencia-dominio tal vez encuentre otra expresión en la figura del "empresario de sí mismo". Al decir del psicoanalista Alemán (2016) un empresario de sí mismo vive permanentemente en relación con lo que lo excede, el rendimiento y la competencia ilimitada. A diferencia de los "cuidados de sí" clásicos que apuntaban a protegerse de los excesos (Foucault, 2003), se busca un control sobre las emociones y sobre los otros con el fin de ser más competitivo en el mercado. Resumiendo, un individuo independiente es uno que no necesitaría ser cuidado ni cuidarse a sí mismo. Este ideal resulta desde nuestra perspectiva una ficción. Ya que para sostenerlo es preciso invisibilizar toda una serie de actividades y relaciones que sostienen la vida a diario y que implican la interdependencia.

\section{LO QUE MUEVE AL MUNDO ES EL CUIDADO}

\subsection{Polifonías y polisemias en torno al cuidado}

Así como los colectivos de personas con discapacidad han promovido la noción de independencia y autonomía (Fine y Glendinning, 2005), los desarrollos teóricos del feminismo han puesto al cuidado en 
el centro (Gilligan, 1985; Tronto, 2007; Carrasco y otros, 2011). El cuidado es un término polisémico y multidimensional, no existiendo consenso ni univocidad en su definición. En la literatura especializada en el tema es posible identificar una rica diversidad de vertientes, así como de disciplinas (sociología, psicología, filosofía, ecología, enfermería, entre otras) y abordajes trans e interdisciplinarios abocados a su estudio. Asimismo, es posible situar los inicios del estudio sistemático en torno a este tema alrededor de la década de 1980 con el surgimiento de la ética feminista del cuidado. Esta corriente dentro de los estudios de la ética forma parte de un contexto más amplio de replanteamiento y reflexión crítica exhaustiva que los feminismos realizaron en diferentes campos de estudio desde la perspectiva de género.

Las diferentes aportaciones sobre el tema varían en sus definiciones sobre el cuidado. Algunas elaboraciones lo definen como una forma de trabajo, asimilable o no a otras formas del trabajo remunerado. Estos aportes tienen como uno de sus principales antecedentes los debates en torno al trabajo doméstico y reproductivo surgidos en el marco de los activismos feministas europeos desde fines de la década de 1960 (Carmona, 2019).

En el debate contemporáneo, los estudios sobre el "trabajo de cuidado" abarcan un amplio abanico. Desde las perspectivas que lo estudian como trabajo destinado a asistir a las personas en "situación de dependencia" en el desarrollo y bienestar de su vida cotidiana (Battyánhy, 2015; Sojo, 2011; Rossel, 2016), hasta aquellas que afirman una concepción ampliada del mismo. Estas últimas sostienen que este trabajo se define por poner en su centro la atención hacia el otro y esta atención puede estar presente en otros oficios que no se definen específicamente como de cuidado (Borgeaud, 2018).

La psicóloga social francesa Pascale Molinier afirma que el trabajo de cuidado se refiere a una dimensión presente en todas las actividades de servicio, en el sentido de servir, ocuparse, prestar atención a otro (Molinier, 2011). Se trata de una subjetividad y una ética del cuidado (Molinier y Legarreta, 2016) entramada con la actividad. Para la autora, el cuidado se sitúa entre el trabajo y la ética, aunque otorga prioridad en su definición a la primera dimensión al poner su énfasis en la actividad más que en la disposición y/o actitud afectiva. De este modo, cuidar de otro no es solo preocuparse intelectual o afectivamente, sino ante todo hacer algo, producir un trabajo que contribuya a mantener o preservar su vida. En el mismo sentido, Thomas (2011) utiliza el plural "cuidados" y sostiene que los mismos están relacionados con los trabajos centrados en las personas. Los definirá como una prestación de apoyo, remunerada o no, en la cual intervienen actividades que implican un trabajo y estados afectivos.

Otras perspectivas abarcan bajo la categoría cuidado tanto la dimensión ética-relacional como la dimensión referida a actividades concretas, sin otorgar mayor peso específico a algunas de estas dimensiones. De este modo, ya para 1990 Fisher y Tronto (como se citó en Tronto, 2005) ofrecen la siguiente definición holística acerca del cuidado, se trata de:

una actividad de especie que incluye todo aquello que hacemos para mantener, continuar y reparar nuestro «mundo» de tal forma que podamos vivir en él lo mejor posible. Ese mundo incluye nuestros cuerpos, nuestros seres y nuestro entorno, todo lo cual buscamos para entretejerlo en una red compleja que sustenta la vida (Tronto, 2005, p. 234).

Por último, otras elaboraciones teóricas que destacamos hacen hincapié en la dimensión ética, así como en la posibilidad de pensar al cuidado en tanto paradigma socioecológico (Boff, 2002; 2012). Desde nuestra perspectiva, el cuidado se entiende en un sentido amplio. Designa la fragilidad de toda existencia y la necesidad de sostenerla mediante múltiples recursos y redes: afectivas y materiales. De esta forma, está relacionado con la vulnerabilidad propia de todos los sujetos, condición ontológica del ser humano y elemento constitutivo de sus experiencias y existencias (Benasayag y Schmit, 2010; Angelino, 2014; López, 2014). 


\subsection{Perspectiva de la condición humana basada en la vulnerabilidad/fragilidad}

La filosofía feminista contemporánea ha producido relevantes aportes a la reflexión actual sobre la vulnerabilidad en tanto condición universal. Destacan en el ámbito anglosajón, la publicación de Mackenzie, Roger y Dodds titulada Vulnerability. New Essays in Ethics and Feminist Philosophy; en el ámbito académico francés, los estudios de Sandra Laugier; en el contexto de habla hispana, encontramos los aportes de Teresa Martín Palomo.

Mackenzie, Roger y Dodds (2013) analizan que el término vulnerabilidad tiene en la literatura especializada en el tema, al menos dos usos extendidos. El primer sentido del término remite a que nuestros cuerpos son animales, constitutivamente sociales e interdependientes y por ello mismo están sujetos a aflicción y lesiones. El cuerpo se vincula a una socialidad encarnada: somos vulnerables a las acciones de los demás, así como interdependientes respecto a su cuidado, en diversos grados y de acuerdo al momento vital. Esta vulnerabilidad es común a todos los humanos, universal, condición ontológica. Si nos remontamos a la etimología misma del término vulnerabilidad, encontramos este mismo sentido: la posibilidad de ser heridos, puesto que vulnus significa herida.

El segundo sentido del término vulnerabilidad, en cambio, es particularizado. Se focaliza en las situaciones de algunas personas o grupos particulares, respecto a tipos específicos de daño o amenaza proveniente de otros. Analiza las formas de las desigualdades de poder y cómo estas hacen que algunos agentes sean vulnerables a daños o explotación por otros. Sin embargo, el primer sentido del término vulnerabilidad, como condición universal, no se agota en la posibilidad de sufrir daño. Según la filósofa feminista Butler (2014): "Indica una condición más amplia de dependencia e interdependencia que cambia la manera dominante de entender ontológicamente al sujeto corporizado" (p. 11). En otro de sus escritos sobre el tema, Butler (2017) nos recuerda que vulnerabilidad remite a receptividad, a una empatía que se despliega a través del tiempo, a cierta porosidad para poder recibir a los otros y sentir lo que a sus cuerpos les sucede. Se trata de un término que permite nombrar una experiencia de desposesión que se da a través de nuestros diversos sentidos, un salir de nosotros mismos. El cuerpo se presenta como un sitio de contacto con el otro, así como de exposición.

\subsection{La ética feminista del cuidado}

Los desarrollos de la llamada "ética del cuidado" (Gilligan, 1985; Held, 2006) permiten comprender al cuidado como un modo de relación con el otro. Ética, en su etimología remite a ethos, es decir, actitud, modo de relacionarse. Desde la visión que ofrece la ética feminista del cuidado, se designa un tipo de pensamiento que valora la preservación de los vínculos. Se trata de una ética feminista en tanto aprecia y reivindica las experiencias históricamente asociadas a las mujeres, en relación con el tejido de un pensamiento ligado al cuidado de la vida. Se propone la transformación social con base a las prácticas asociadas al cuidado, las cuales permanecen subordinadas y desvalorizadas en el marco del sistema patriarcal (Eisler, 1990).

Muchas de las principales teóricas de esta corriente se han dedicado a postular el cuidado más allá de las relaciones próximas e íntimas. Ejemplo de ellos son los aportes de Sarah Ruddick (1989) sobre maternidad y procesos de paz; Nel Noddings (2003) en torno al cuidado y la educación; Joan Tronto $(2017 ; 2018)$ sobre cuidado y sistemas políticos y económicos; Irene Comins Mingol (2008) en referencia a la filosofía de la paz y la ética del cuidado; Virginia Held (2006) en torno a la ética del cuidado en ámbitos públicos. Existe consenso en reconocer el surgimiento de esta perspectiva ética a partir de la publicación del libro In a different voice en 1982. Su autora es la destacada investigadora de la Universidad de Harvard, Carol Gilligan. En esta obra la psicóloga discute las principales teorías del desarrollo moral vigentes hasta ese momento, a partir de tres grandes estudios empíricos realizados. La investigadora plantea que, además de una ética de la justicia, basada en la evaluación de las situaciones a partir de conceptos abstractos, formales y universales, es posible 
detectar una forma de pensamiento narrativa y contextual. La misma halla sus principales características en la responsabilidad dentro de las relaciones, así como la búsqueda de mantenimiento de los vínculos (Gilligan, 1985).

A diferencia de la ética de la justicia, un modo de pensamiento basado en formulaciones abstractas y universales, la ética del cuidado es concreta y singular. Es la ética del caso por caso o de la situación por situación. Más que aplicar fórmulas predefinidas para evaluar una situación, propone adentrarse en la misma, evaluando qué podemos hacer juntos en cada encuentro. Supera la dicotomía razón-afectos. Apela al mantenimiento de las redes de relaciones para poder resolver problemas y/o situaciones de la vida cotidiana (Gilligan, 1985). En este mismo sentido, afirma Najmanovich (2018):

El cuidado de sí y del otro sólo puede nacer de los encuentros vitales, nunca de los ideales. Cuando olvidamos al ser vivo complejo para buscar la pureza del ideal, abandonamos toda posibilidad de cuidado. Porque cuidar no es "hacer el bien", sino potenciarnos mutuamente, "hacer sinergia". El otro de la moral sólo es legítimo cuando se atiene a la escala de valores vigentes. El otro de la ética es un ser vivo con el que se establece un vínculo en el que nos afectamos mutuamente y puede potenciarnos o despotenciarnos. Nada está dado a priori, ni en abstracto, todo fluye al ritmo de los encuentros y de la comprensión que tenemos de nuestra existencia necesariamente común (p. 30).

Desde la perspectiva de la ética del cuidado, podemos arribar a la conclusión de que todos los seres humanos somos interdependientes, es decir, necesitamos de otros para desarrollar nuestras actividades de la vida diaria, en mayor o menor grado. En el caso de algunas personas con discapacidad, se vuelve particularmente evidente esta necesidad de asistencia/apoyo para desarrollar ciertas actividades, pero lejos de constituir una excepción a la condición humana, nos revela una ontología relacional que es compartida por todo lo vivo. Desde la perspectiva de la interdependencia y el cuidado, la vida es frágil, lo cual nos exige el despliegue de una ética del cuidado como modo de toda relación. Tal como afirma Palacios (2008):

Por supuesto que, en realidad, nadie es completamente independiente: vivimos en un estado de interdependencia mutua. Por lo tanto, la dependencia de las personas con discapacidad no es una característica que las diferencie del resto de la población, sino solo en una cuestión de grado. Pero nos enfrentamos a un grave problema cuando el significado de dependencia asignado por los profesionales y el asignado por las propias personas con discapacidad es diferente (p.142).

En este sentido, creemos que la noción de cuidado nos permite partir de una concepción social y afectiva de las personas. El mundo no está constituido por individuos aislados y racionales que compiten en el mercado, sino por redes de personas que se encuentran entrelazadas y satisfacen sus necesidades. En palabras de Tronto (2007):

De repente, no vemos sólo que el mundo está constituido por individuos autónomos que persiguen fines racionales y proyectos de vida, también vemos que está hecho de personas enmarañadas en redes de compromiso y comprometidas con la atención de las necesidades de otras personas a su alrededor. Esto no significa que cada actividad del mundo se refiere al cuidado, pero muchas lo son (p. 289).

Lo que puede parecer una verdad de perogrullo, el hecho de que sin el otro no podemos sostener nuestras vidas, es algo, sin embargo, continuamente negado por el orden socioeconómico vigente. $\mathrm{Al}$ menos podemos señalar dos grandes motivos para esta negación. Por un lado, se trata de invisibilizar las múltiples tareas que desarrollan de manera cotidiana fundamentalmente las mujeres. En este sentido, los debates promovidos por los feminismos europeos, en torno al trabajo doméstico y reproductivo en las décadas de 1960 y 1970 , serán decisivos para nombrar al conjunto de estas actividades desarrolladas en los hogares como trabajo (Dalla y James, 1972; Federici, 2013; 2018). Así como explicitar la existencia de una división sexual del trabajo (Rubin, 1986).

Por otro lado, ante los valores propios de nuestras sociedades, el cuidado aparece como un asunto de minorías y de poco valor. Es decir, una práctica destinada a algunas vidas definidas por su "dependencia": las de personas con discapacidad "dependientes", niños y adultos mayores. 


\subsection{De la dependencia/independencia a la interdependencia}

Desde la perspectiva del presente trabajo, la fragilidad es condición de toda vida. Esta afirmación no implica desconocer que existen personas con necesidades de cuidado más intensas y/o específicas, ya sea por su situación y/o momento vital. Sin embargo, no se trata de una dicotomía entre personas independientes cuidadoras-personas y dependientes cuidadas, sino de una diferencia en intensidad y/o especificidad en los cuidados. La interdependencia hace referencia al modo mismo en que la vida puede desplegarse, sostenerse y florecer.

Por ello, para Draper (2018), la interdependencia se actualiza "en la trama misma que nos compone como seres finitos y no solamente en la situación «excepcional» de quienes no pueden valerse por sí para desarrollar las tareas cotidianas" (p. 176). En este sentido, afirma que "es importante insistir en el paso de la mirada de la crisis (de cuidados) y la excepcionalidad (casos de dependencia por edad o enfermedad), a la percepción de la malla de cuidados que funcionan para que sea posible la vida" (p. 176).

En la literatura especializada sobre ética del cuidado, existen autoras como Feder Kittay $(1999 ; 2011)$ que asocian cuidado con la dependencia, pero otras comprenden la interdependencia como el punto de partida para poder pensar el cuidado (Tronto, 2007; Held, 2006). Feder Kittay (1999) emplea el término dependencia para hacer referencia a un estado temporal o extendido, consistente en la necesidad del otro para satisfacer las necesidades básicas. Sin otro que asiste, la persona dependiente no estaría en condiciones de sobrevivir por sí misma ni de prosperar. Si bien esta dependencia puede agravarse por los contextos culturales y los prejuicios sociales existentes, lo cierto es que para Kittay la misma corresponde a situaciones relacionadas con la infancia, la vejez, la enfermedad o la discapacidad. Sin embargo, la destacada especialista en ética del cuidado, reconoce la existencia de una "dependencia anidada", que daría cuenta de la necesidad de responder socialmente del cuidado de quienes cuidan. De allí que proponga el modelo de la "doula" 5 como encuadre posible para ser extendido en la trama social. Aunque no reconozca que las personas en situación de dependencia puedan practicar cuidados de sí y de otros, asume que todas las personas necesitan cuidado, al sugerir que las sociedades cuiden de quienes cuidan a las personas en situación de dependencia.

Desde nuestra perspectiva, la dicotomía entre independientes y dependientes se erige en función de la supuesta autosuficiencia de algunos. Aquellos que aparecen como autosuficientes, generalmente los sujetos masculinos sin discapacidades, que se desempeñan en trabajos fuera del hogar, dependen de una red vincular, material y afectiva que les permite sostenerse (Pérez, 2012). Es así que podemos afirmar que el cuidado, lejos de ser una responsabilidad asumida por todos y definida como necesidad de todos, es concebida como asunto de algunos pocos. Sin embargo, nadie queda por fuera del cuidado, no solo por el hecho de que pudimos crecer ya que otra persona nos alojó, nombró y cuidó. Tampoco porque al envejecer, o si presentamos una discapacidad, necesitamos cuidados. Menos aún porque requerimos cuidados cuando enfermamos.

El cuidado no es solo una práctica relacionada con los polos de la vida (niñez y vejez) o con situaciones excepcionales, manteniéndose un gran paréntesis en el medio llamado adultez. "Aunque muchos adultos autónomos piensan que están cuidando de ellos mismos, de hecho, cada uno de nosotros está en una red compleja de relaciones" (Tronto, 2007, p. 299). El cuidado, en su dimensión de tarea concreta y también como actitud de ocupación, preocupación, responsabilidad y compromiso afectivo con el otro (Boff, 2002; 2012), con la naturaleza (Boff, 2012) y con uno mismo (Foucault, 2003), es lo que sostiene al mundo y nuestros seres de manera cotidiana. Teje y reteje el mundo en común. En todas sus dimensiones: materiales y afectivas. Como afirma la politóloga norteamericana Tronto (2007), todos estamos inmersos en una compleja red de relaciones de cuidado. "Hay un flujo continuo que representa cuánto cuidado necesita una persona, y no una dicotomía entre los que son cuidados y los que cuidan” (Tronto, 2007, p. 299).

El concepto de cuidado nos permite "repensar los vínculos $[. .$.$] más allá de su dimensión mercantil o$ utilitarista, sino desde el reconocimiento de la propia fragilidad y necesidad del otro" (Pié y Solé, 2011, p. 10). El cuidado del otro, en torno al par dicotómico cuidador independiente y persona cuidada dependiente, 
desconoce que todo ser humano necesita ser cuidado e invisibiliza las múltiples situaciones de cuidado que se despliegan en cada encuentro entre personas, más allá de los roles que puedan existir. "Así pues, lo relevante en esta cuestión es que la vulnerabilidad y la dependencia son características propias del ser humano, son lo que lo constituyen como tal" (Pié y Solé, 2011, p. 10).

\subsection{La distinción entre cuidado y asistencia}

Es importante señalar, por último, que el cuidado nunca puede devenir en una plataforma de despliegue de una opresión. Como nos recuerda el reconocido filósofo búlgaro Todorov (2004), la dignidad de las personas se relaciona con su autonomía, es decir, el ejercicio de la voluntad. El cuidado no puede lesionar la dignidad de las personas. En este sentido, resulta relevante destacar la distinción entre cuidado y asistencia propuesta por los colectivos de personas con discapacidad. Los mismos han acuñado este término como modo de escapar de la captura paternalista con la que muchas veces es interpretado y llevado adelante el cuidado. Configurándose como control y opresión, más que como potenciación mutua en la interdependencia.

El concepto de "asistencia" hace referencia a una especie de "prótesis" para llevar adelante ciertas decisiones de la vida cotidiana (Kittay, 2011) o incluso para el tejido de las propias decisiones (Kittay y Carlson, 2010). Tal como afirma Romañach Cabrero (2012):

\footnotetext{
Esta disquisición resulta relevante ya que la palabra «cuidado» tiene una clara connotación médica, que genera rechazo dentro del colectivo de personas discriminadas por su diversidad funcional, que ven en su contenido la tradición médica que establece una jerarquía en la relación médico/paciente, una jerarquía que ha trascendido de lo médico a lo social dejando una impronta de desigualdad, discriminación y minusvaloración del colectivo (p. 57).
}

Mas allá del término que se adopte, el desafío radica en "cómo combinar interdependencia con niveles suficientes de autonomía, entendida como capacidad de decidir sobre la propia vida, sabiendo que la autonomía personal y la autonomía social mantienen una complicidad [...] una no puede darse sin la otra" (Pérez, 2012, p. 44). En términos de Martín Palomo (2010), la búsqueda de autonomía implica el cuestionamiento a la idea de unidireccionalidad del cuidado. Es decir, la existencia de una persona que cuida y otra que recibe cuidados de forma pasiva. El concepto de autonomía nos permite asimismo pensar en un cuidado que la fomente.

\section{ConClusiones: HACIA UNA NOCIÓN DE AUTONOMÍA EN INTERDEPENDENCIA}

La revisión que realizamos de los conceptos planteados tiene como objetivo central poder pensar y vivenciar nuestra común interdependencia. Siguiendo a Najmanovich (2017), se trata de concebir a los otros como condición de posibilidad y no solo como fuente de hostilidad (aunque a veces sean hostiles). Desde nuestra perspectiva la independencia no solo es imposible, sino que, además, es una ficción. Solo gozamos de una autonomía ligada y nuestra libertad depende de la calidad de los intercambios y no de su ausencia (Najmanovich, 2017). Muchas de las dicotomías de la modernidad, ser humano-naturaleza, mentecuerpo, independencia-dependencia, normalidad-anormalidad, capacidad-discapacidad, razón-emoción, ya no resultan eficaces para comprender de manera cabal el universo del que formamos parte y, por tanto, tampoco a nosotros mismos y nuestros contextos.

La perspectiva de la ética del cuidado conmueve los modos tradicionales de reflexión en torno a la condición humana, al colocar en primera plana el carácter social e interdependiente del ser humano, contribuyendo a desmontar el ideario de sujeto fundante de la modernidad: un sujeto racional, aislado, desprovisto de afectos y de relaciones que lo constituyen y le permiten sostenerse. Asimismo, se manifiesta como una ética alternativa a la del neoliberalismo (Tronto, 2017), entendido este último como un régimen económico y productor de subjetividades en torno al utilitarismo, la competencia, la independencia 
entendida como autosuficiencia, el desgarramiento de los vínculos y la idea de que la vida puede desarrollarse en soledad y aislamiento.

La ética del cuidado se deriva de una ontología de la interdependencia y la fragilidad como condiciones humanas. "En lugar de pensar en las personas como homo economicus, tiene mucho más sentido entenderlas como hominens carens, es decir, como personas que viven en relaciones de cuidado mutuo" (Tronto, 2018, p. 11). Por lo tanto, concluimos este escrito afirmando que las condiciones de posibilidad para un ejercicio y desarrollo de la autonomía, en personas con o sin discapacidades, siempre están dadas en una trama de relaciones. Cualquier intento de afirmar la autonomía en la no-dependencia, en la independencia, implica no reconocer nuestro carácter de sujetos complejos (complejo en su etimología deriva de complexus, es decir, lo que está tejido junto).

A partir de las aproximaciones anteriores podemos decir que es a través de la interdependencia que se funda la autonomía. Es decir, es mediante las redes vinculares en las que estamos inmersos que se pueden componer relaciones que habiliten u obstaculicen el desarrollo de la autonomía. Las formulaciones provenientes de la filosofía feminista han propuesto reconceptualizar y reestructurar el concepto de autonomía individual. De este modo se propone la "autonomía relacional” (MacKenzie y Stoljar, 2000) como concepto alternativo. El mismo abarca una amplia gama de perspectivas que coinciden en contemplar las dimensiones intersubjetivas de la individualidad. Este modo de pensar la autonomía preserva la importancia de la autodeterminación y la emergencia de la singularidad, al mismo tiempo que resguarda la consideración de la comunidad en la cual todos estamos entramados y las redes de cuidado en las que nos sostenemos. Dicho en otros términos: la autonomía nunca es sin otros. Vivimos, inevitablemente, en un mundo tramado por relaciones (Perlo, 2014).

Por otra parte, el concepto de autonomía relacional nos convoca a la consideración de las dimensiones sociales, económicas, políticas y jurídicas de la estructura social en la que una persona se encuentra entramada. En este sentido, es relevante incorporar como perspectiva, para pensar la relación entre autonomía y cuidado, los derechos que todas las personas poseen por el solo hecho de ser personas.

A lo largo de esta reflexión propusimos aportes conceptuales para pensar la autonomía en íntima relación con una ética del cuidado y una perspectiva de la interdependencia. Se trata de una "autonomía en interdependencia" que lejos está de situarse en equivalencia con una ontología individualista que desconoce el modo mismo en que efectivamente las vidas son sostenidas. Se trata, entonces, de ensayar y explorar marcos de interpretación alternativos a la constelación de sentidos con los que la autonomía se ha asociado tradicionalmente: individuo, libertad negativa, racionalidad, deliberación, argumentación. Por el contrario, buscamos entramarla con conceptos como cuidado, interdependencia, comunidad, singularidad, con el fin de poder situar las posibilidades en la autonomía de todas las personas, sin que nadie quede excluido.

Así, más que en oposición, autonomía y dependencia se encuentran entrelazadas deviniendo en interdependencia. Siendo este acople característico de todos los seres humanos. La consideración de todos los sujetos como interdependientes abona la percepción de todas las personas como dependientes de múltiples cuidados y oficiando de cuidadores a la vez, en mayor o menor medida y de acuerdo a las circunstancias. El cuidado y la autonomía deben encontrar sus puntos de articulación. Es, tal vez, la forma en la que podemos asegurar que el cuidado nunca se convierta en el buen nombre para coartar libertades ni posibilidades de tomar decisiones acerca de cómo vivir la propia vida.

\section{Agradecimientos}

A Vidi y Catalina. A la Revista de Poesía ZL y sus integrantes, quienes inspiraron este escrito. A la Dra. Claudia Perlo por sus diálogos profundos y enriquecedores. 


\section{ReFERENCIAS}

Agulló, C., Arroyo, J., Ema, J., Gámez, C., Gómez, E., Jiménez, P., ... y Colina, M. (2011). Cojos y precarias haciendo vidas que importan. Madrid, España: Traficantes de sueños.

Alemán, J. (2016). Horizontes neoliberales en la subjetividad. Buenos Aires, Argentina: Editorial Grama.

Angelino, M. A. (2014). Mujeres intensamente habitadas. Ética del cuidado y discapacidad. Paraná, Argentina: Editorial Fundación La Hendija.

Batthyány, K. (2015). Las políticas y el cuidado en América Latina. Una mirada a las experiencias regionales. Santiago de Chile: CEPAL.

Benasayag, M. y Schmit, G. (2010). Las pasiones tristes: sufrimiento psiquico y crisis social. Buenos Aires, Argentina: Editorial Siglo XXI.

Boff, L. (2002). El cuidado esencial. Ética de lo humano, compasión por la tierra. Madrid, España: Editorial Trotta.

Boff, L. (2012). El cuidado necesario. Madrid, España: Editorial Trotta.

Borgeaud, N. (2018). Introducción. En El trabajo de cuidado (pp. 13-30). Buenos Aires: Fundación Medifé.

Butler, J. (junio de 2014). Repensar la vulnerabilidad y la resistencia. En S. Villarmea (Coord. Gral.), Filosofia, conocimiento y prácticas feministas. Conferencia inaugural llevada a cabo en el XV Simposio de la Asociación Internacional de Filósofas (IAPh), Alcalá de Henares, España. Recuperado de https://www.youtube.com/ watch?v=hEjQHv0R6rQ

Butler, J. (2017). Vulnerabilidad corporal, coalición y la política de la calle. Nómadas, (46), 13-29. Recuperado de http://www.scielo.org.co/pdf/noma/n46/0121-7550-tuoma-46-00013.pdf

Candioti, M. (2012). Responsabilidad por el otro y ante el otro en el ámbito de lo común. En G. Frigerio y G. Diker (Comps.), Educar: posiciones acerca de lo común (pp. 265-284). Paraná, Argentina: Editorial Fundación La Hendija.

Carmona, D. (2019). La resignificación de la noción de cuidado desde los feminismos de los años 60 y 70 . En-claves del pensamiento, 13(25), 104-127. Recuperado de http://www.scielo.org.mx/pdf/enclav/v13n25/2594-1100enclav-13-25-104.pdf

Castoriadis, C. (2006). Figuras de lo pensable. México: Fondo de Cultura Económica.

Cerri, C. (2015). Dependencia y autonomía: una aproximación antropológica desde el cuidado de los mayores. Athenea digital 15(2), 111-140. doi: https://doi.org/10.5565/rev/athenea.1502

Comins, I. (2008). La ética del cuidado y la construcción de la paz. Barcelona: Editorial Icaria.

Contino, A. M. (2017). La autonomía en el territorio de la discapacidad. Revista Crítica, 2(3), 12-27. Recuperado de https://criticapsicologia.unr.edu.ar/wp-content/uploads/2018/12/La-autonomia-en-elterritorio-de-la-discapacidad-Contino.pdf

Dalla, M. y James, S. (1972). El poder de la mujer y la subversión de la comunidad. México: Siglo XXI.

Draper, S. (2018). Tejer cuidados a micro y macro escala entre lo público y lo común. En C. Vega, R. Martínez y M. Paredes (Eds.), Cuidado, comunidady común: experiencias cooperativas en el sostenimiento de la vida (pp.167-185). Madrid, España: Traficantes de Sueños.

Eisler, R. (1990). El cáliz y la espada: nuestra historia, nuestro futuro. Santiago de Chile: Cuatro Vientos.

Federici, S. (2013). Revolución en punto cero. Trabajo doméstico, reproducción y luchas feministas. Madrid, España: Traficantes de Sueños.

Federici, S. (2018). El patriarcado del salario. Madrid, España: Traficantes de Sueños.

Fine, M. y Glendinning, C. (2005). Dependence, Independence or Inter-dependence? Revisiting the Concepts of 'Care' and 'Dependency'. Ageing \& Society, 25(4), 601-621.

Foucault, M. (2003). La ética del cuidado de sí como práctica de la libertad. Barcelona, España: Paidós.

Gilligan, C. (1985). La moral y la teoría. Psicología del desarrollo femenino. México: Fondo de Cultura Económica. 
Guzmán, F. (2010). Diversidad funcional. Análisis en torno a la propuesta de un cambio terminológico para la discapacidad. En M. Navarro, B. Estévez y A. Sánchez (Eds.), Claves actuales de pensamiento (pp. 137-154). Madrid: CISC, Plaza y Valdés.

Guzmán, F., Toboso M. y Romañach, J. (2010). Fundamentos éticos para la promoción de la autonomía: hacia una ética de la interdependencia. Alternativas. Cuadernos de Trabajo Social, (17), 45-61.

Held, V. (2006). The Ethics of Care: Personal, Political and Global. New York, United States: Oxford University Press. Kittay, E. (1999). Love's Labor: Essays on Women, Equality, and Dependency. New York, United States: Routledge.

Kittay, E. y Carlson, L. (2010). Cognitive Disability and Its Challenge to Moral Philosophy. New Jersey, United States: Wiley-Blackwell.

Kittay, E. (2011). The Ethics of Care, Dependence, and Disability. Ratio Juris, 24(1), 49-58.

López, S. (2014). Debates en la teoría feminista contemporánea: sujeto, ética y vida común. Quaderns de Psicologia, 16(1), 45-53. Recuperado de https://www.quadernsdepsicologia.cat/article/view/v16-n1-lgil/1224-pdf-es

MacKenzie, C., Rogers, W.y Dodds, S. (2013). Vulnerability. New Essays in Ethics and Feminist Philosophy. New York, United States: Oxford University Press.

MacKenzie, C. y Stoljar, N. (2000). Relational Autonomy: Feminist Perspectives on Automony, Agency, and the Social Self. New York: Oxford University Press.

Martín, M. T. (2010). Autonomía, dependencia y vulnerabilidad en la construcción de la ciudadanía. Zerbitzuan: revista de servicios sociales, (48), 57-69.

Molinier, P. (2011). Antes que todo, el cuidado es un trabajo. En L. Arango y P. Molinier (Eds.), El trabajo y la ética del cuidado (pp. 41-64). Medellín, Colombia: La Carreta Editores.

Molinier, P. y Legarreta M. (2016). Subjetividad y materialidad del cuidado: ética, trabajo y proyecto político. Papeles del CEIC (Centro de Estudios sobre la Identidad Colectiva), 1, 1-14.

Najmanovich, D. (2017). El sujeto complejo: La condición humana en la era de la red. Utopía y Praxis Latinoamericana. Revista Internacional de Filosofía y Teoría Social, 22(78), 25-48. Recuperado de https:// produccioncientificaluz.org/index.php/utopia/article/view/22632

Najmanovich, D. (2018). Nosotros y los otros: diversidad y cuidado de sí y del otro. Revista Leitura: Teoria \& Prática, 36(73), 17-31. Recuperado de https://ltp.emnuvens.com.br/ltp/article/view/689/451

Noddings, N. (2003). Caring: A Feminine Approach to Ethics and Moral Education. California, United States: University of California Press.

Oliver, M. (1990). The Politics of Disablement. Hong Kong: Macmillan Press.

Palacios, A. (2008). El modelo social de discapacidad: orígenes, caracterización y plasmación en la Convención Internacional sobre los Derechos de las Personas con Discapacidad. Madrid, España: Editorial Cinca.

Pérez, A. (2012). Crisis multidimensional y sostenibilidad de la vida. Investigaciones Feministas, 2, 29-53. doi: https:// doi.org/10.5209/rev_INFE.2011.v2.38603

Perlo, C. (2014). Hacer ciencia en el siglo XXI. Despertar del sueño de la razón. Paraná, Argentina: Editorial Fundación La Hendija.

Pié, A. y Solé, J. (octubre de 2011). Deconstruir la discapacidad para repensar la autonomía: propuestas para una pedagogía de la interdependencia. En M. Buxarrais (Presidencia), XII Congreso Internacional de Teoría de la Educación. Ponencia llevada a cabo en la Universidad de Barcelona, España.

Quinn, G. y Degener, T. (2002). Derechos humanos y discapacidad. Uso actual y posibilidades futuras de los instrumentos de derechos humanos de las Naciones Unidas en el contexto de la discapacidad. Nueva York y Ginebra: Naciones Unidas.

Romañach, J. (2012). Ética y derechos en la práctica diaria de la atención a la dependencia: autonomía moral vs. autonomía física. En A. Pié, J. Romañach y R. Ros (Coords.), Deconstruyendo la dependencia: propuestas para una vida independiente (pp. 47-74). Barcelona, España: Universitat Oberta de Catalunya.

Rossel, C. (2016). Desafios demográficospara la organización social del cuidado y las políticas públicas. Santiago de Chile: Naciones Unidas. 
Rubin, G. (1986). El tráfico de mujeres: notas sobre la "economía política” del sexo. Nueva Antropología, 8(30), 95-145. Recuperado de https://www.caladona.org/grups/uploads/2007/05/El\%20trafico\%20de\%20mujeres2.pdf

Ruddick, S. (1989). Maternal Thinking: Towards a Politics of Peace. Toronto: The Women's Press.

Sojo, A. (2011). De la evanescencia a la mira: el cuidado como eje de políticas y de actores en América Latina. Santiago de Chile: CEPAL.

Toboso, M. y Guzmán, F. (2010). Cuerpos, capacidades, exigencias funcionales...y otros lechos de Procusto. Politica y Sociedad, 47(1), 67-83.

Todorov, T. (2004). Frente al límite. México: Editorial Siglo XXI.

Thomas, C. (2011). Deconstruyendo los conceptos de cuidados. En C. Carrasco, C. Borderías y T. Torns (Eds.), El trabajo de cuidados. Historia, teoria y políticas (pp. 145-176). Madrid, España: Catarata.

Tronto, J. (2005). Cuando la ciudadanía se cuida: una paradoja neoliberal del bienestar y la desigualdad. En M. Iradier y V. Gasteiz (Eds.), Congreso Internacional Sare 2004: “¿Hacia qué modelo de ciudadania?” (pp. 231-254). España: Emakunde/Instituto Vasco de la Mujer. Recuperado de http://www.emakunde.euskadi.eus/ contenidos/informacion/publicaciones_jornadas/es_emakunde/adjuntos/sare2004_es.pdf

Tronto, J. (2007). Assistência Democrática e Democracias Assistenciais. Sociedade e Estado, 22(2), 285-308. doi: http://dx.doi.org/10.1590/S0102-69922007000200004

Tronto, J. (2017). There is an alternative: homines curans and the limits of neoliberalism. International Journal of Care and Caring, 1(1), 27-43. doi: https://doi.org/10.1332/239788217X14866281687583

Tronto, J. (2018). La democracia del cuidado como antídoto frente al neoliberalismo. En C. Domínguez, H. Kohlen y J. Tronto (Eds.), El futuro del cuidado. Comprensión de la ética del cuidado y práctica enfermera (pp. 7-19). Barcelona: Ediciones San Juan de Dios.

\section{Notas}

1. Utilizamos la nominación "personas con discapacidad" contenida en la Convención Internacional de Derechos de las Personas con Discapacidad (CDPD), en cuya elaboración participaron colectivos de personas con discapacidad. Con relación al concepto de discapacidad, adscribimos a las reflexiones que resultaron del proyecto de investigación Discapacidad y exclusión social: un abordaje interdisciplinario, dirigido por la Dra. Ana Rosato y radicado en la Facultad de Trabajo Social de la Universidad Nacional de Entre Ríos, Argentina (UNER). En el marco de estas reflexiones, la discapacidad es una categoría dentro de un sistema de clasificación. El mismo produce sujetos a partir de la idea de "normalidad única" que funciona, tanto como parámetro de medición de lo normal/ anormal, así como de ideología legitimadora de relaciones de asimetría y desigualdad.

2. La investigación se desarrolla con la dirección de la Doctora en Humanidades mención en Educación, Claudia Liliana Perlo, en el marco de los estudios del Área de Aprendizaje y Desarrollo Organizacional del Instituto Rosario de Investigaciones en Ciencias de la Educación (CONICET/UNR).

3. Es necesario señalar que, desde algunas perspectivas, se distingue entre déficit y discapacidad. En cambio, en otras, se cuestiona el concepto mismo de déficit, ya que se considera que solo se puede leer un déficit en una persona a partir de un determinado modelo de ser humano al que se supone completo.

4. Se trata de un foro de reflexión filosófica y de lucha por los derechos de las personas con diversidad funcional. Tiene su origen en España a mediados del año 2001, cuyo objetivo principal es impulsar el movimiento de vida independiente. La palabra Divertad combina los valores de la diversidad con la libertad.

5. Se trata de una mujer que acompaña, en los primeros momentos, a otra mujer que se ha convertido en madre, ocupándose de que la misma se encuentre bien y ayudándola. En otros términos, la doula se ocupa de cuidar a quien cuida.

\section{FinANCiAmiento}

Fuente: Consejo Nacional de Investigaciones Científicas y Técnicas de Argentina (CONICET) Beneficiario: Autonomía e interdependencia. La ética del cuidado en la discapacidad 
Lic. Diego Carmona Gallego. Autonomía e interdependencia. La Ética del Cuidado en la discapacidad

CC BY-NC-ND 